\title{
FAILURE OF NARCOTIC ANTAGONIST TO ALTER ELECTROACUPUNCTURE MODIFICATION OF HALOTHANE ANAESTHESIA IN THE DOG
}

\author{
Aye-Aye L. Tay, Chin-Kai Tseng, Nathan L, Pace, K.C. Wong and Benecia C. Hong-Goka
}

\section{Abstract}

Sixteen dogs were used to study the analgesic effects of electroacupuncture. Electroacupuncture lowered halothane MAC significantly $(1.21 \pm 0.04$ to $1.05 \pm 0.05$ per cent, $\mathrm{p}<0.005$ ). Reversibility of this effect by narcotic antagonist was then studied, using naltrexone $5 \mathrm{mg} \cdot \mathrm{kg}^{-1}$ injected intravenously $(10 \mathrm{dogs})$ or $0.5 \mathrm{mg} \cdot \mathrm{kg}^{-1}$ intrathecally ( 3 dogs). We failed to see any reversal of the effect of electroacupuncture on MAC. Narcotic antagonist reversibility of acupuncture effect is taken currently to imply endorphin mediation. Possible explanations for our result include an electroacupuncture analgesia not mediated by endorphins.

KEY WORDS: ACUPUNCTURE, narcotic antagonist.

Many eXPlanations for the efficacy of acupuncture and electroacupuncture have been proposed. Currently, the favoured hypothesis relates acupuncture and electroacupuncture analgesia to the production of endorphins. ${ }^{1,2}$ Naloxone or naltrexone (a more potent narcotic antagonist with longer duration of action than naloxone) reversibility of acupuncture effect is taken to imply endorphin mediation. We have previously demonstrated lowering of the minimum alveolar anaesthetic concentration (MAC) for halothane in the dog by electroacupuncture. ${ }^{3}$ In the present study we sought to determine any reversibility of this electroacupuncture phenomenon by narcotic antagonist.

\section{METHODS}

The determination of MAC followed the method of Eger. ${ }^{4}$ Mongrel dogs unselected for

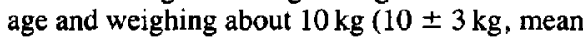
$\pm \mathrm{SD}$ ) were anaesthetized with halothane in oxygen. Without the use of muscle relaxants or

Aye-Aye L. Tay, M.D., Research Fellow; ChinKai Tseng, M.D., Visiting Research Professor; Nathan L. Pace, M.D., Associate Professor; K.C. Wong, M.D., Ph.D., Professor and Chairman; Benecia C. Hong-Goka, M.D., Assistant Professor; Department of Anesthesiology, University of Utah School of Medicine, 50 North Medical Drive, Salt Lake City, Utah.

Presented in part at the annual meeting of the American Society of Anesthesiologists, St. Louis, Missouri, October 1980.

Correspondence and reprint requests to: Nathan $L$. Pace, M.D.,

Can. Anaesth. Soc. J., vol. 29, no. 3, May 1982 other drugs, the trachea was intubated with a tightly fitting, cuffed tracheal tube. Anaesthesia was continued and the dogs were ventilated mechanically. A femoral arterial catheter was inserted for arterial blood gas sampling and continuous pressure monitoring. A foreleg vein was cannulated for fluid administration. Rectal temperature was taken with a glass thermometer and temperature was maintained between $36^{\circ}-$ $38^{\circ} \mathrm{C}$ with a heating lamp and blanket.

Respiratory gases were aspirated from a catheter inserted down the tracheal tube and monitored continuously on an infrared gas analyzer (Beckman LB-2) for halothane. A given end-tidal anaesthetic concentration was maintained for at least 15 minutes before testing. The stimulus used was a $25 \mathrm{~cm}$ haemostat clamped on the shaved tail $5-10 \mathrm{~cm}$ from its base until the rachet caught; the tail was moved continuously with the haemostat for 60 seconds. Gross, purposeful, muscular movements (jerking, twisting, running or clawing) were considered a positive response; coughing, swallowing, chewing, stiffening and hyperventilation were not considered positive reponses. ${ }^{4}$ Two observers viewed all animal responses to stimulation. MAC was taken to be the concentration midway between the highest concentration allowing and the lowest concentration preventing a positive response. MAC was always determined in duplicate; the time required for a duplicate determination was about two hours. MAC was expressed as a fractional concentration of one atmosphere ( 760 tom). As we had previously 
demonstrated the absence of any time effect on the modification of halothane MAC by electroacupuncture, ${ }^{3}$ we did not use a crossover experimental design.

Following a control duplicate MAC determination, 10 animals received electroacupuncture for 30 minutes and then for an additional two hours while MAC was again determined in duplicate. Electrocupuncture was done bilaterally at San-Yin-Chiao (over the medio-posterior aspect of the tibia, one-third of its length from the distal end). San-Yin-Chiao is a traditional acupuncture point for the caudal region. An equivalent acupuncture locus has been suggested for the dog (Figure 1). Bilateral electroacupuncture is thought to increase potency. Stainless steel $6.6 \mathrm{~cm}$ acupuncture needles (Igarashi Ika Kogyo, Ltd, , Tokyo, Japan) were inserted intramuscularly. The electrical stimulus was a filtered square wave; pulse width was $1 \mathrm{msec}$ at $2 \mathrm{~Hz}$ and $0.7 \mathrm{msec}$ at $200 \mathrm{~Hz}$. Four to six volts was the maximum amplitude, and this produced minimal local muscle twitch. Current was not measured. The stimulation pattern was a $2 \mathrm{~Hz}$ signal continuously for five minutes alternating with five minutes of a $200 \mathrm{~Hz}$ signal given for three seconds followed by a one second rest (Figure 2). MAC was determined a third time immediately following administration of naltrexone $5 \mathrm{mg} \cdot \mathrm{kg}^{-1}$ intravenously; an additional intravenous bolus of naltrexone $2.5 \mathrm{mg} \cdot \mathrm{kg}^{-1}$ was given after 45 minutes. Electroacupuncture was continued throughout.

To examine the possibility that naltrexone applied directly near the spinal cord might alter the acupuncture effect, another group of six dogs was prepared in a similar fashion. Following determination of control MAC in three dogs, naltrexone $0.5 \mathrm{mg} \cdot \mathrm{kg}^{-1}$ was injected intrathecally and MAC was redetermined. In the other three dogs, a control MAC was determined, then electroacupuncture was done as described above and MAC was redetermined. While electroacupuncture was continued, naltrexone $0.5 \mathrm{mg} \cdot \mathrm{kg}^{-1}$ was injected intrathecally and MAC was determined once more.

To establish a continuous spinal catheter, an 18 gauge $90 \mathrm{~mm}$ Crawford epidural needle was introduced in the midline at the 6th lumbar interspace or at the lumbosacral junction. The needle was advanced until the dura was punctured and there was free flow of cerebrospinal fluid (CSF). Then a 20 gauge 36 inch radiopaque epidural catheter was advanced without difficulty $15 \mathrm{~cm}$ past the needle hub. The needle was

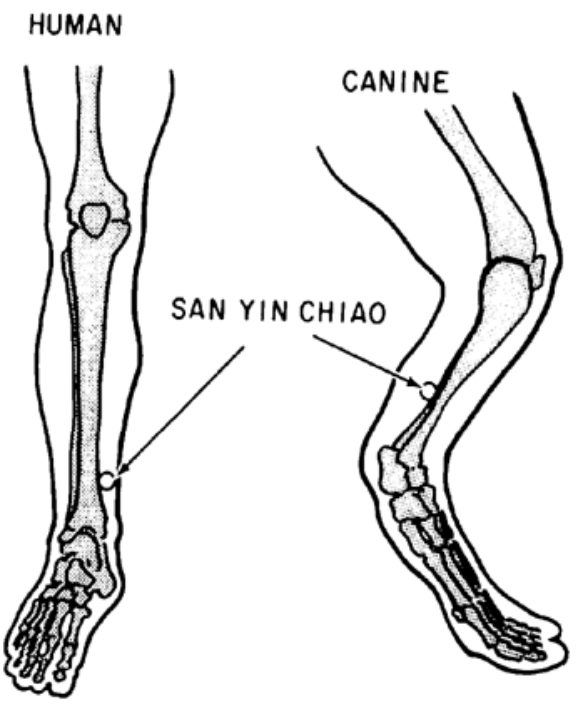

Figure 1 Acupuncture locus.

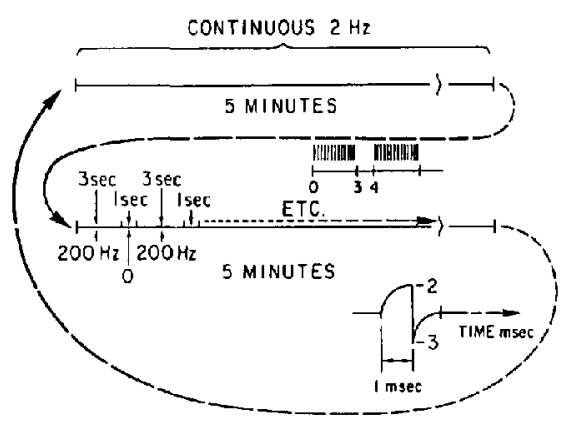

I = STIMULUS -FILTERED SQUARE WAVE

2 =PULSE WIOTH-I msec AT $2 \mathrm{~Hz} ; 0.7 \mathrm{msec}$ AT $200 \mathrm{~Hz}$

$3=4-6$ VOLTS MAXIMUM AMPLITUOE; MINIMAL LOCAL MUSCLE TWITCH

FlGURE 2 Electroacupuncture stimulation pattern.

then removed and the catheter secured to the skin with a suture. An intrathecal catheter tip position was again verified by free flow of CSF. The catheter tip was estimated to be at the first lumbar vertebra.

Changes in MAC in each group was evaluated by a paired t-test; $p$ values less than 0.05 were considered statistically significant.

\section{RESULTS}

The MAC of halothane during electroacupuncture was significantly lower $(\mathrm{p}<0.005)$ 
TABLE I

alterations in Halothane MaC by Electroacupuncture and Intravenous
Naltrexone

(Per cent ATM; Mean \pm SEM) $(\mathrm{n}=10)$

\begin{tabular}{ll}
\hline \hline Control (C) & \\
$1.21 \pm 0.04$ per cent & C vs EA: $t=4.04 ; p<0.005$ \\
Electroacupuncture (EA) & \\
$1.05 \pm 0.05$ per cent & C vs EA $+\mathrm{N}: \mathrm{t}=5.27 ; \mathrm{p}<0.001$ \\
$\begin{array}{l}\text { Electroacupuncture Plus Naltrexone } \\
\left(5 \mathrm{mg} \cdot \mathrm{kg}^{-1}+2.5 \mathrm{mg} \cdot \mathrm{kg}^{-1}\right)(\mathrm{EA}+\mathrm{N})\end{array}$ \\
$1.06 \pm 0.04$ per cent & EA vs EA $+\mathrm{N}: \mathrm{t}=0.47 ; \mathrm{p}>0.60$ \\
\hline
\end{tabular}

TABLE II

Alterations in Halothane MAC ay Electroacupuncture and INTRathecal NALTREXONE (Per cent ATM; Mean \pm SEM)

\begin{tabular}{ll}
\hline \hline $\mathrm{n}=3$ Control $(\mathrm{C})$ & \\
$1.17 \pm 0.05$ per cent & $\mathrm{C}$ vs $\mathrm{N}: \mathrm{t}=1.0 ; \mathrm{p}>0.4$ \\
Naltrexone $0.5 \mathrm{mg} \cdot \mathrm{kg}^{-1}(\mathrm{~N})$ & \\
$1.14 \pm 0.02$ per cent & \\
$\mathrm{n}=3$ Control $(\mathrm{C})$ & $\mathrm{C}$ vs EA: $\mathrm{t}=25 ; \mathrm{p}<0.005$ \\
$1.21 \pm 0.05$ per cent & \\
Eectroacupuncture (EA) & $\mathrm{C}$ vs EA $+\mathrm{N}: \mathrm{t}=25 ; \mathrm{p}<0.0005$ \\
$0.96 \pm 0.04$ per cent & \\
Electroacupuncture Plus Naltrexone & \\
$0.5 \mathrm{mg} \cdot \mathrm{kg}^{-1}$ (EA $\left.+\mathrm{N}\right)$ & EA vs EA $+\mathrm{N}: \mathrm{t}=0 ; \mathrm{p}=1.0$ \\
$0.96 \pm 0.04$ per cent & \\
\hline
\end{tabular}

than the control MAC (Tables I and II). The intravenous administration of naltrexone, 5 $\mathrm{mg} \cdot \mathrm{kg}^{-1}$, or intrathecal naltrexone 0.5 $\mathrm{mg} \cdot \mathrm{kg}^{-1}$, did not reverse the analgesic effect of electroacupuncture. Intrathecal naltrexone 0.5 $\mathrm{mg} \cdot \mathrm{kg}^{-1}$ by itself did not change MAC.

\section{Discussion}

Highly specific opiate receptors on neuronal membranes have been discovered in the brain. ${ }^{5}$ A further search has revealed endogenous polypeptides which bind to these opiate receptors. ${ }^{6}$ These peptides, which have now been synthesized and shown to be morphinomimetic when administered to animals ${ }^{7}$ are referred to as opioid peptides or endorphins; the pentapeptides, a subgroup of opioid peptides, are known as enkephalins. The pure narcotic antagonist naloxone appears to reverse all effects of exogenously administered endorphins. The neurochemical role of the large polypeptide endorphins is unclear, although considerable evidence suggests enkephalins may have a role as neurotransmitters. ${ }^{8.9}$

The existence of endorphins or enkephalins with a neurophysiological role would demand that direct pharmacological actions of a pure narcotic antagonist be seen. Yet traditionally the pure narcotic antagonist naloxone has been considered to have no important effects of its own, except to antagonize the actions of exogenous opioid drugs. ${ }^{8,9}$ Another possibility must be considered; perhaps certain appropriate circumstances must be imposed on the experimental subject to activate the endogenous opioid system before a clear direct action of naloxone could be expected. Pharmacological activity of naloxone is then taken as necessary (but not sufficient) evidence of endorphin mediation. Alternatively, observations of increased cerebral endorphin/enkephalin production are also suggestive of an endorphin/enkephalin mediated process. These approaches have been applied to studies of acupuncture and electroacupuncture phenomena.

Mayer, et al.$^{10}$ demonstrated complete reversal of acupuncture analgesia by naloxone in an experimental pain study. ${ }^{10}$ In a similar study (painful dental stimulation), Chapman and Benederti found a partial reversal by naloxone of electroacupuncture analgesia. ${ }^{11}$ Both reports suggested an endorphin role in the observed analgesia. By contrast, a recently reported study 
by Chapman, et al. failed to see naloxone reversal of electroacupuncture analgesia. ${ }^{12}$ Also, two clinical pain studies observed electroacupuncture analgesia without consistent naloxone reversibility. Sjölund and Eriksson found reversal in only three of five chronic pain sufferers. ${ }^{13}$ Woolf, et al. found reversal in one of six patients with acute pain. ${ }^{14}$

Attempts to show increased endorphin content in human CSF following acupuncture at present gives inconsistent results. Sjölund, et $a l^{15}$ reported an increase in material with opioid activity in human lumbar CSF after electroacupuncture for lumbar pain; however, there was no change in CSF opioid content following electroacupuncture for facial pain (trigeminal neuralgia). ${ }^{15}$ Clement-Jones, et al. suppressed heroin withdrawal symptoms by electroacupuncture in heroin addicts. Although there was no change in $\beta$-endorphin levels in lumbar CSF following electroacupuncture, the met-enkephalin content of lumbar CSF did increase. ${ }^{16}$ In Sjölund's report the increased opioid activity was not met-enkephalin but was a material of large molecular size. ${ }^{15}$

Possible endorphin mediation of acupuncture has also been studied in animals. Pomeranz and Chiu ${ }^{17}$, Woolf, et al. ${ }^{18}$ and Toda, et al. ${ }^{19}$ demonstrated naloxone reversibility of electroacupuncture analgesia in mice and rats, respectively. Cheng and Pomeranz ${ }^{20}$ have also demonstrated that levonaloxone, but not dextronaloxone reverses electroacupuncture analgesia. By contrast, McLennan, et al. ${ }^{21}$ observed no naloxone-induced changes in rabbits receiving acupuncture; in that study interference with tryptaminergic mechanisms did prevent the development of electroacupuncture analgesia. Acupuncture at the specific loci Jen Chun (Go-26) and Tsu San $\mathrm{Li}(\mathrm{St}-36)$ in dogs has been shown to produce a sympathomimetic and parasympathomimetic effect respectively on the cardiovascular system. Lee, et al. observed no naloxone reversibility of the sympathomimetic effects of acupuncture at Jen Chun (Go-26). ${ }^{22}$

Recently Cheng and Pomeranz ${ }^{23}$ and Sjölund and Eriksson ${ }^{24}$ showed that, at low frequency stimulation $(2-4 \mathrm{~Hz})$, electroacupuncture analgesia was reversible with naloxone; but at high frequency stimulation $(50-200 \mathrm{~Hz})$ naloxone did not reverse the electroacupuncture effect. High frequency electroacupuncture analgesia was partially blocked by parachlorophenylalanine (a serotonin synthesis inhibitor). ${ }^{23}$

However, the work of other investigators does not fit tidily into this pattern. Woolf, et al. observed reversibility with naloxone at high stimulation frequencies $(100 \mathrm{~Hz}){ }^{18}$ Chapman, et al. observed no naloxone reversibility at low frequencies $(2 \mathrm{~Hz}){ }^{12}$ Toda, et al. observed reversibility at an intermediate frequency ( 45 Hz). ${ }^{19}$

The inconsistencies in the clinical and experimental data reviewed above leave doubt that the endorphin systems contribute to electroacupuncture analgesia. The study of acupuncture is not simple. For example, it is still not clear whether naloxone and/or naltrexone have non-specific analeptic effects. ${ }^{25,26}$ If analeptic effects exist, the logic of naloxone reversal experiments is obviously flawed. It is likely that, depending on stimulation parameters and locus of stimulation, different mechanisms can operate. ${ }^{9}$ Many central nervous system mechanisms of pain and analgesia have been proposed. ${ }^{27,28}$

We failed to see any reversal of electroacupuncture analgesia by systemic or lumbar intrathecal naltrexone. Under the conditions of our experiment the endorphin/enkephalin system remains unproved as a major component of electroacupuncture analgesia. The most likely explanation for our results compared to previous reports is an electroacupuncture analgesia not primarily mediated by endorphins.

\section{REFERENCES}

1. LIAO, S.J. Recent advances in the understanding of acupuncture. Yale J. Biol. Med. 51: 55-65 (1978).

2. BowERS, J.Z. Reception of acupuncture by the scientific community: from scom to a degree of interest. Comp. Med. East West 6: 89-96 (1978).

3. Tseng, C.-K., Tay, A.-A.L., Pace, N.L., WESTENSKOW, D.R. \& WONG, K.C. Electroacupuncture modification of halothane anaesthesia in the dog, Can. Anaesth. Soc. J. 28: 125-128 (1981).

4. Eger, E.I. II, SAidman, L. J. \& Brandstater, B. Minimum alveolar anesthetic concentration: a standard of anesthetic potency. Anesthesiology 26: 756-763 (1965)

5. SNYDER, S.H. Opiate receptors in the brain. N Engl. J. Med. 296: 266-271 (1977).

6. GoldsteIN, A. Opioid peptides (endorphins) in pituitary and brain. Science 193: 1081-1086 (1976).

7. Malick, J.B. \& Goldstein, J.B. Analgesic activity of enkephalins following intracerebral administration in the rat. Life Sci. 20: 827-832 (1977).

8. Frederickson, R.C.A. Enkephalin pentapeptides - a review of current evidence for a physiological role in vertebrate neurotransmission. Life Sci. $21: 23-42$ (1977). 
9. Terenius, L. Endogenous peptides and analgesia. Ann. Rev. Pharmacol. Toxicol. 18: 189-204 (1978).

10. Mayer, D.J., Price, D.D. \& Rafi, A. Antagonism of acupuncture analgesia in man by the narcotic antagonist naloxone. Brain Res. 121: 368-372 (1977)

11. Chapman, R. \& Benedetti, C. Analgesia following transcutaneous electrical stimulation and its partial reversal by a narcotic antagonist. Life Sci. 21: $1645-1648$ (1977).

12. Chapman, CR Colpitts, Y M Benedett, C., KitaefF, R. \& Gehrig, J.D. Evoked potential assessment of acupunctural analgesia: attempted reversal with naloxone. Pain 9: 183-187 (1980).

13. Siölund, B. \& ERIKsson, M. Electroacupuncture and endogenous morphines. Lancet 2: 1085 (1976).

14. WOOLF, C.J. Mitchell, D. MYers, R A. \& BARRETT, G.D. Failure of naloxone to reverse peripheral transcutaneous electroanalgesia in patients suffering from acute trauma. S. Afr. Med. J. 53: 179-180 (1978).

15. Suölund, B., Terenius, L. \& Eriksson, M. Increased cerebrospinal fluid levels of endorphins after electroacupuncture. Acta Physiol. Scand. 100: 382-384 (1977).

16. Clement-Jones, V., MCLAughlin, L., LOWRY, P.J., Besser, G.M. \& ReEs, L.H. Acupuncture in heroin addicts: changes in metenkephalin and $\beta$-endorphin in blood and cerebrospinal fluid. Lancet 2: 380-383 (1979).

17. Pomeranz, B. \& ChIU, D. Naloxone blockade of acupuncture analgesia: endorphin implicated. Life Sci. 19: 1757-1762 (1976)

18. Woolf, C.J., BarRetT, G.D., Mitchell, D. \& MYERS, R.A. Naloxone-reversible peripheral electroanalgesia in intact and spinal rats. European J. Pharmacol. 45: 311-314 (1977).
19. TODA, K., SUdA, H., ICIOKA, M. \& IRIKI, A. Local electrical stimulation: effective needling points for suppressing jaw opening reflex in rat. Pain 9: 199-207 (1980).

20. Cheng, R.S.S. \& Pomeranz, B.H. Electroacupuncture analgesia is mediated by stereospecific opiate receptors and is reversed by antagonists of type I receptors. Life Sci. 26: 631-638 (1980).

21. Mclennan, H, Gilfillan, K, \& Heap, Y. Some pharmacological observations on the analgesia induced by acupuncture in rabbits. Pain 3: $229-238(1977)$

22. LeE, D.C., IChiYanaGi, K., LeE, M.O. \& Morris, C.E. Can naloxone inhibit the cardiovascular effect of acupuncture? Can. Anaesth. Soc. J. 26: 410-414 (1979)

23. Cheng, R. \& Pomeranz, B. Electroacupuncture and analgesia could be mediated by at least two pain-relieving mechanisms: endorphin and nonendorphin systems. Life Sci. 25: 1957-1962 (1979).

24. SJOLLUND, B \& ERIKSSON, M. The influence of naloxone on analgesia produced by peripheral conditioning stimulation. Brain Res. 173: 295 301 (1979).

25. Furst, Z., Foldes, F.F. \& KNoll, J. The influence of naloxone on barbiturate anesthesia and toxicity in the rat. Life Sci. 20:921-926 (1977).

26. HortTa, A. \& Carino, M.A. Analeptic and antianaleptic effects of naloxone and naltrexone in rabbits. Life Sci. 23: 1681-1686 (1978).

27. Mayer, D.J. \& PrICE, D.D. Central nervous system mechanisms of analgesia. Pain $2: 379$ 404 (1976).

28. Messing, R.B. \& LYTLE, L.D. Serotonincontaining neurons: their possible role in pain and analgesia. Pain 4: 1-21 (1977).

RÉSUME

On a étudié sur seize chiens les propriétés analgésiques de l'acupuncture. L'électroacupuncture a abaissé le MAC de l'halothane de façon significative (de $1.21=0.04$ à 1.05 \pm 0.05 pour cent, $P<0.05$ ). On a par la suite évalué la réversibilité de cet effet par les narcotiques antagonistes en injectant par la voie veineuse du naltrexone $5 \mathrm{mg} \cdot \mathrm{kg}^{-1}$ (10 chiens) ou $0.5 \mathrm{mg} \cdot \mathrm{kg}^{-1}$ par la voie intrathécale ( 3 chiens). Aucun renversement de l'effet de l'électroacupuncture n'a été observé sur le MAC. On a cru jusqu'à maintenant que la réversibilité de l'acupuncture par les antagonistes narcotiques nécessitent une médication endorphinique. Une explication possible des résultats rapportés ici peut laisser supposer que au contraire l'analgésie par acupuncture ne se fait pas par médiation endorphinique 